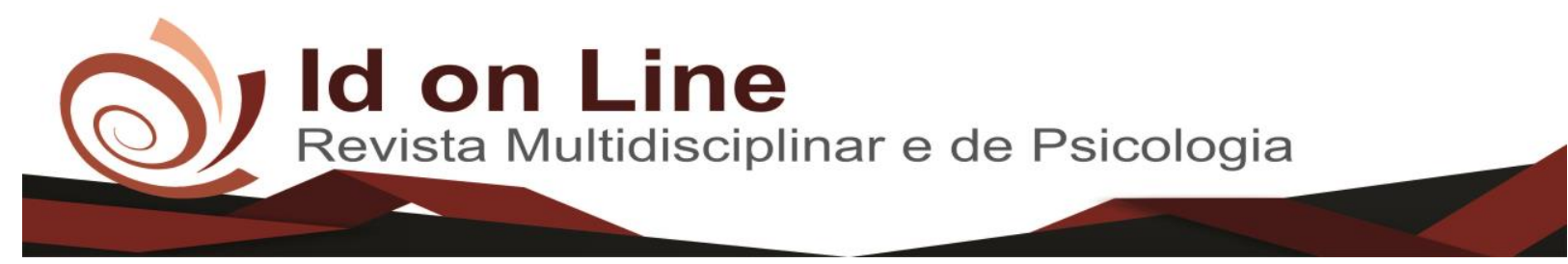

Artigo

\title{
O Papel do Cuidador na Identificação dos Fatores Relacionados ao Suicídio de Idosos
}

\author{
Maria Raquel de Oliveira Alcântara ${ }^{1}$; Thércia Lucena Grangeiro Maranhão ${ }^{2}$;
} Ana Olivia de Oliveira Marinho ${ }^{3}$ : Leonarda Carvalho de Macedo ${ }^{4}$

\begin{abstract}
Resumo: O artigo teve como objetivo identificar o papel do cuidador na identificação dos possíveis fatores que levam pessoas idosas a cometerem suicídio dentro do seu contexto familiar e social, tendo como objetivos específicos: identificar, quais fatores estão relacionados a tentativas de suicídio no idoso; analisar de que forma os fatores de risco do suicídio podem ser amenizados da vida do idoso e compreender a importância do acolhimento familiar e psicológico no processo de envelhecimento saudável. Foi realizada uma pesquisa bibliográfica em artigos científicos e livros, utilizando a abordagem qualitativa. Assim, conclui-se que a presença da família e de um cuidador é de suma importância no processo de envelhecimento e na identificação dos comportamentos suicidas, onde a falta de atenção e amor dos familiares, são os fatores mais comuns para o desencadeamento de ideações, comportamentos e suicídios em idosos. A pesquisa não pretende esgotar o tema, mas contribuir para o desenvolvimento de novas pesquisas dentro dos fatores de riscos encontrados.
\end{abstract}

Palavras-chave: Idoso. Suicídio. Cuidador. Família.

\section{The Role of the Caregiver in the Identification of the Factors Related to the Elderly Suicide}

\begin{abstract}
The article aimed to identify the role of the caregiver in identifying the possible factors that lead elderly people to commit suicide within their family and social context, with specific objectives: to identify, which factors are related to suicide attempts in the elderly; to analyze how the risk factors of suicide can be softened from the life of the elderly and to understand the importance of family and psychological care in the process of healthy aging. A bibliographic research was conducted in scientific articles and books, using the qualitative approach. Thus, it is concluded that the presence of the family and a caregiver is of utmost importance in the aging process and in the identification of suicidal behaviors, where the lack of attention and love of family members are the most common factors for triggering ideations, behaviors and suicides in the elderly. The research does not intend to exhaust the theme, but to contribute to the development of new research within the risk factors found.
\end{abstract}

Keywords: Elderly. Suicide. Caregiver. Family.

\footnotetext{
${ }^{1}$ Graduada do curso de Psicologia do Centro Universitário Doutro Leão Sampaio (Unileão). E-mail: raqueloliveira.12@hotmail.com

${ }^{2}$ Psicóloga. Professora dos cursos de Psicologia e Gestão de RH do Centro Universitário Dr. Leão Sampaio- UNILEÃO.Especialista em Gestão do Trabalho e da Educação pela Escola de Saúde Pública do Estado do Ceará. Mestra em Ciências da Saúde pelo Programa de PósGraduação da Faculdade de Medicina do ABC. E-mail: thercia@leaosampaio.edu.br;

${ }^{3}$ Médica pela Universidade de Pernambuco - UPE. Contato: anamarinho89@gmail.com;

${ }^{4}$ Psicopedagoga pela Fundação Francisco Mascarenhas e Mestre em Educação pela Hispano Guarani - PY. Professora no município de Araripina - PE. Contato: leovalho2008@hotmail.com.
} 


\section{Introdução}

O aumento da longevidade traz desafios para a população, fato que demanda cada vez mais profissionais capacitados para os cuidados com o idoso. Desta forma, torna-se necessário um preparo de pessoas para realizarem esse trabalho, em decorrência da situação de fragilidade que se encontra a maioria dos idosos, por questões de doenças. Esse cuidador nem sempre será um familiar, por isso, busca-se um profissional que ajudem na melhoria de vida do idoso, considerando-se assim, um cuidador formal (CONCEIÇÃO, 2010).

O suicídio já é considerado um problema de saúde pública, sendo definido por um ato realizado por a própria vítima, para finalizar algum sofrimento ou comunicar algo podendo ter várias causas e motivações para sua ocorrência, sendo difícil determina-lo e analisa-lo por apenas um aspecto (FUKUMITSU, KOVÁCS, 2015).

Assim, a psicologia busca compreender o ato suicida a partir de fatores que podem ser denominados como: precipitantes, internos e o contexto sociocultural. Esses fatores podem levar o psicólogo a aproximar-se de situações na vida do indivíduo, percebendo o potencializador do ato, ou dos comportamentos que o antecedem (RIGO, 2013).

Percebeu-se que com a presença de um cuidador na vida do idoso, muitos de seus pensamentos e comportamentos relacionados a vida, a morte, ao sentido da existência e até mesmo sobre querer tirar sua própria vida pode ser demostrado, identificando aspectos que podem ser observados na perspectiva da prevenção do adoecimento mental e promoção de saúde.

O estudo levanta alguns questionamentos sendo eles: o suicídio é fator de risco para idosos? Os fatores sociais causam impacto no processo de envelhecimento? Os cuidadores e os familiares podem perceber comportamentos suicidas no idoso, podendo evitar?

A fim de responder estes questionamentos, o artigo tem como objetivo principal identificar, o papel do cuidador na identificação dos possíveis fatores que levam pessoas idosas a cometerem suicídio dentro do seu contexto familiar e social, tendo como objetivos específicos identificar quais fatores estão relacionados a tentativas de suicídio no idoso; analisar de que forma os fatores de risco do suicídio podem ser amenizados da vida do idoso e compreender a importância do acolhimento familiar e psicológico no processo de envelhecimento saudável.

O estudo foi realizado a partir do interesse pessoal em compreender, o papel dos cuidadores na vida do idoso, percebendo os fatores relacionados ao suicídio dentro do contexto 
social em que ele está inserido e como os familiares podem contribuir para um envelhecimento saudável. Observou-se no meio acadêmico curiosidade e falta de conhecimento sobre o assunto, onde pode possibilitar um estudo mais aprofundado do público específico, com base nos fatores de riscos encontrados.

Para chegar aos resultados do estudo, foi realizado uma pesquisa bibliográfica com abordagem qualitativa, onde através de levantamento bibliográfico em artigos, teses e cartilhas relacionados ao tema, trouxe a reflexão dentro dos objetivos propostos.

Assim, entende os processos ocorridos no desencadeamento de ideações suicidas, trazendo uma base de conhecimento para a sociedade e aos familiares e cuidadores, ajudando-os a entender o que pode ser feito para minimizar esse processo sem negligenciar suas maneiras de enfrentar as mudanças ocorridas nessa fase.

\section{Referencial Teórico}

\section{Cuidadores de Idosos}

É perceptível a mudança no perfil populacional, destacando o aumento no número de idosos e a transformação nas estruturas familiares. Miranda, Mende e Silva (2016) relata sobre os problemas apresentados na velhice, que não necessariamente estão ligados a doenças, mesmo com os avanços tecnológicos que permitem que a população acesso a vários serviços que proporcionam uma melhor qualidade de vida nesse ciclo.

Percebe-se que com a chegada da velhice, aumenta a necessidade de uma pessoa cuidadora, que sempre está vinculada a uma pessoa idosa ou com deficiência, sendo um trabalho desenvolvido em locais como instituições ou casas abrigo, onde ajudam os idosos em seus cuidados pessoais, pois a grande parte são totalmente dependentes (GOMEZ; REY, 2015).

Pode se entender por cuidado toda atenção, zelo, preocupação e responsabilidade, buscando servir ao outro naquilo que lhe dê resultado, percebendo na outra pessoa o que lhe precisa, como ela é e suas limitações, tendo a capacidade de atender as necessidades da outro ser em cuidado, levando em conta as suas particularidades, indo a diante dos cuidados físicos, abrangendo as emoções, a história de vida daquele ser, percebendo até onde o outro consegui ir 
sozinho, ajudando e estimulando-o a conseguir a autonomia para o desenvolvimento de suas tarefas. A formula está na paciência e no tempo (BRASIL, 2008).

Desta maneira inicia a atividade profissional do cuidador de idosos instituído no Art. $1^{\circ}$ da Lei N 7332 de 14 de julho 2016 da Assembleia Legislativa do Estado do Rio de Janeiro como uma atividade que pode ser desempenhada em instituições públicas, privadas ou domiciliar. Esse cuidador no exercício de sua profissão deve promover ao idoso bem-estar, melhoria na qualidade de vida e sua participação social, assim como ajudar nas atividades diárias afim de prevenir complicações em suas necessidades, cuidado com acidentes domésticos, estimulando o desenvolvimento da comunicação e de atividades de lazer, informando aos familiares responsáveis as condições de saúde do idoso e orientando sempre que preciso de cuidados médicos (BRASIL, 2016).

Então, para que aja uma melhoria na qualidade de vida do idoso dependente, o papel do cuidador é de suma importância, avaliando seu grau de comprometimento, sem negligenciar sua forma de vivenciar essa fase, indo de encontro as necessidades encontradas, permitindo que cuidadores façam parte do convívio do idoso, seja ele familiar ou não.

\section{Cuidadores Familiares}

Percebendo-se que a idade avançada é marcada por a presença de doenças crônicas podendo levar a incapacidade de atividades comuns desencadeando uma dependência, a presença de um cuidador para auxiliar o idoso em sua movimentação diária, ocorre de maneira voluntária ou não, sendo esse papel, na maioria das vezes, desenvolvido por familiares próximos; esse trabalho quando realizado por essas pessoas, é desenvolvido dentro dos lares, onde a pessoa cuidadora abarca todos os cuidados necessários, permitindo uma vida saudável para aquele ser dependente (LEME et al. 2011).

Assim, tomar a responsabilidade de cuidar do idoso familiar, pode gerar grande sobrecarga e afetar esse indivíduo em termos físicos, psicológicos e social, tendo em vista a falta de preparo para os cuidados. A família sendo afetada por a dependência, ou doença, da pessoa idosa causam impactos nas relações familiares, na rotina e nos cuidados desempenhados por esses (NOGUEIRA et al. 2012). 
Portanto, entende-se o papel da família no cuidado com o idoso como um dever na sociedade brasileira. Considera-se que mesmo embora isso ocorra de maneira habitual, a falta de preparo, recurso e adequação por parte desses familiares, tem levado a busca de um cuidador formal como um suporte na sobrecarga, no desgaste e no estresse adquirido no tempo de cuidado (COUTO; CASTRO; CALDAS, 2016).

Estudos sobre cuidadores apontam que, geralmente a tarefa de cuidar do idoso é designada aos familiares através de quatro critérios: parentesco, gênero, proximidade física e afetividade. Assim, pensando em reduzir os gastos financeiros em relação a hospitalizações e institucionalização, a opção é a permanência do idoso em seu lar, sobre os cuidados da família (KARSCH, 2003).

Verifica-se que para que os cuidados desenvolvidos permitam ao idoso uma vida saudável, o familiar cuidador precisa ser capacitado para realizar os procedimentos corretos em situações de risco, assim como ter uma relação com os profissionais de saúde, recebendo apoio para suprir a sobrecarga nos períodos de cuidado, sem comprometer a saúde do idoso (COUTO; CASTRO; CALDAS, 2016).

Durantes os cuidados com o idoso, vários sentimentos são desenvolvidos permitindo uma maior aproximação. Diante disso, Freitas et al. (2008) cita o desgaste e as dificuldades encontrados nesse processo de cuidar, mas destaca a dedicação depositada, gerando uma divisão entre a vida de ambos e até entre outros familiares, pois as atenções passam a ser voltada apenas para o idoso dependente, a fim de não deixar que nada lhe falte.

A tarefa de cuidar pode surgir naturalmente, mas que pode ser visto com dificuldades por os familiares não estarem preparados para esse papel de cuidador, e durante convívio surgem desafios familiares, por isso procura-se apoio emocional e equilíbrio para enfrentar o desgaste obtido no período de cuidado. Diante deste contexto, os profissionais de saúde possuem a tarefa de dar suporte no âmbito emocional e no processo saúde/doença frente as necessidades encontradas, para que assim possam desenvolver um cuidado que possibilite uma qualidade de vida para o idoso (SCALCO, 2013). 


\section{Cuidadores Formais}

A necessidade de uma dedicação integral a pessoa idosa, leva muitas famílias a buscarem ajuda de pessoas fora do contexto familiar para desenvolver esse papel de cuidador, podendo ser conhecido como "cuidador formal”. Essa pessoa contratada pela família realizará serviços específicos adquiridos por cursos e treinamentos para prestar aquela prática de cuidar (LEME et al. 2011).

Então, percebendo as mudanças na estrutura familiar, a contratação de cuidadores formais tonou-se uma possibilidade no contexto das famílias que possuem um idoso que necessita de assistência e uma maior atenção (BATISTA et al. 2014). Assim, na Política Nacional de Saúde da Pessoa Idosa mostra os cuidados que devem ser prestados a essa população, priorizando a atenção voltada a aqueles que se encontram em situações de fragilidade (BRASIL, 2006).

Batista et al. (2014) relata que a procura por instituições também se torna uma solução para os casos em que não se encontra mais alternativas de cuidados familiares, assim, cresce a cada dia os atendimentos prestados a idosos em seus domicílios, sendo estabelecidos por Políticas Públicas, em que possibilita a continuação da população idosa em sua comunidade.

O cuidado prestado promove ajuda no desenvolvimento das atividades diárias, favorecendo autonomia. O cuidador precisa abranger características como habilidade para a realização das tarefas, disponibilidade e principalmente o afeto para com as fragilidades sociais e emocionais do idoso (BATISTA et al. 2014).

Diante de alguns conflitos nem sempre esses cuidados são prestados no domicílio do idoso, pois as mudanças ocorridas na dinâmica familiar impossibilitam esse cuidar domiciliar. Assim, as Instituições de Longa Permanência surgem como uma opção para a continuação de vida dessa população (ANTUNES et al. 2012).

As Instituições realizam práticas de cuidados a pessoas idosas, onde os cuidadores contratados auxiliam nas atividades básicas do idoso, visando a diminuição dos agravos das doenças e na manutenção da saúde (REIS et al. 2015).

O papel dos cuidadores formais é fundamental dentro das famílias que não possuem disponibilidade para esse papel, contudo a falta de conhecimentos e condições de trabalho inadequado, dificulta esse trabalho, sendo necessário formação e qualificação para um bom 
cuidado com o idoso (COLOMÉ et al. 2011), além do afeto para atender as necessidades emocionais nesse processo (BATISTA et al. 2014).

\section{Ideação Suicida}

Para chegar ao suicídio propriamente dito alguns comportamentos são desencadeados descritos como ideações suicidas. Turecki (1999) cita que as ideações são pensamentos, desejos e ideias em relação a morte, onde o comparecimento desse comportamento aponta para uma maior observação para a avaliação dos riscos de suicídio no contex to do indivíduo.

Assim como o suicido é considerado um problema de saúde pública, as ideações entram na categoria de risco para a saúde, pois são preditoras para o ato ser consumado, se configurando como o primeiro passo desse processo de comportamentos, e tentativas. As ideações podem estar relacionadas as consequências desfavoráveis de episódios enfrentados na vida (SOUZA et al. 2010).

Deve-se ser considerado que as ideações não são facilmente detectadas por observações diretas. Entrevista e estudos relacionados ao assunto, mostram que há uma limitação metodológica, pois em entrevistas face a face, não são comunicados tais comportamentos, pois necessita-se de confiança no entrevistador, sendo mais frequente observar tais comportamentos e ideias, instrumentos que que mantenham o anonimato do entrevistado (BOTEGA et al. 2009).

Os estudos sobre a ideações suicida no idoso, ainda é considerado um problema em sua interpretação, pois esse fenômeno não é relatado pelos idosos em entrevistas. Em suas falas, apresentam relatos de pensamentos de morte, cansaço, falta de sentido e tristeza, mas que ao serem relacionados com o discurso de vida, podem ser associados a ideias e pensamentos suicida ou confundidos com sintomas depressivos (CAVALCANTE; MINAYO, 2010).

Percebe-se então que os pensamentos suicidas antecedem o ato e pode não ser percebido ou ignorado por quem convive com o indivíduo que pensa no ato (ABP, 2014). Esses pensamentos são considerados um fator de risco, pois pesquisas mostram a idealização planejada nos casos de suicídio consumado (ARAUJO; COUTINHO, VIEIRA, 2010).

Dessa forma, as ideações surgem a partir de particularidades do indivíduo, que lhe causam sofrimento e desgaste emocional, buscando como saída os pensamentos e planejamentos 
de como da um fim a esse sofrimento, saindo do meio em que ele está inserido (BARBOSA et al. 2016).

\section{Tentativa de Suicídio}

Assim como as ideações, as tentativas de suicídio apresentam-se como um problema dentro da sociedade, sendo um fenômeno ocorrido por causas múltiplas, complexas e construída por diversos fatores envolvendo o biológico, o pessoal, seu contexto socioeconômico e eventos circunstanciais (MARTINS; MINAYO; TEIXEIRA, 2016).

Para definir as tentativas de suicídio Cavalcante e Minayo (2015) cita os comportamentos suicidas diante das ideações, sendo atitudes não fatais, mas que podem avançar partindo para as tentativas, com atos voltados para a autodestruição, deixando pistas verbais ou comportamentais, mas que podem não resultar em morte. Assim as tentativas são atos induzidos para a autodestruição, mas que não conseguem ser consumado (FIGUEIREDO et al. 2015).

Dessa forma, as tentativas de suicídio ultrapassam o número de suicídios consumados, onde cada caso deve ser analisado de modo particular, verificando os princípios daqueles comportamentos, percebendo em cada um a manifestação de alerta (BOTEGA et al. 2009).

Percebe-se que após uma tentativa de suicídio aumenta-se a chance do indivíduo tentar novamente até conseguir concretizar o ato, sendo a população que merece atenção em busca de prevenção. Por isso, os serviços de saúde dentro da atenção primária, desempenham papel importante para a avaliação dos riscos e em campanhas de prevenção, sendo considerado um problema de saúde pública. Assim o que pode ser destacado são os mitos que existem em relação ao comportamento suicida, sendo um erro desconsiderar a importância da prevenção, as falas do indivíduo em relação a morte e as melhoras após uma crise (MELEIRO; SANTOS; SOUSA, 2009).

Sabe-se que a expectativa de vida da população aumenta, mudando assim o perfil populacional da sociedade. Junto com esse crescimento aumenta-se as tentativas de suicídio entre pessoas idosas, considerando aquelas com idade superior a 60 anos. Por isso, o impacto social que esse fato ocasiona na saúde pública, levam aqueles que fazem parte dos cuidados com pessoas idosas (enfermeiros, familiares, cuidadores), compreenderem os aspectos que levam a 
ocorrência dessas atitudes, para que seja feito uma identificação antecipatória para o desenvolvimento de ações preventivas (BELLASALMA et al. 2012).

\section{Suicídio}

Assim como nascer faz parte da vida do ser humano, morrer do ponto de vista biológico é algo natural e mostra-se com significados simbólicos imprimidos pelos indivíduos ao decorre da história da humanidade, atravessando culturas e valores sociais. Para a civilização moderna, a morte passou a ser sinônimo de fracasso e luta-se para não ser atingida por ela (COMBINATO; QUEIROZ, 2006).

Na sociedade atual o suicídio já é considerado um problema de saúde pública, onde até pouco tempo era um tema tabu para muitas pessoas. A palavra suicídio vem de origem latina sui (si mesmo) e caederes (ação de matar), mesmo não tendo uma definição única, ela se relaciona ao ato consciente realizado por o indivíduo resultando em morte (ARAÚJO; COUTINHO; VIEIRA, 2010).

A definição de suicídio pode ser vista não apenas na visão de autodestruição, de um ato realizado pela própria vítima através de uma ação violenta, mas com comportamentos que de maneira indireta traz o mesmo resultado. Sem generalizar os fatos, o suicídio vem ser o ato realizado de maneira direta ou indireta pela própria vítima, que sabendo o resultado, chegue a morte (DURKHEIM, 2007).

Esse fenômeno encontra-se presente na história da humanidade, sendo resultado de uma interação de vários fatores. Por isso, para se analisar o ato suicida deve-se considerar acontecimentos de forma gradual, pois chegar ao ato é consequência de um processo da vida do indivíduo, que possui influencia social, familiar e individual (MOOZ; VIEIRA, 2016).

Dessa maneira como fase anterior ao suicídio existem os comportamentos suicidas, sendo classificados como: ideação suicida (ideias, ameaças e planejamentos) e o comportamento em si, que segue com as tentativas, até chegar a consumar o ato, levando em consideração que nem sempre esses comportamentos são identificados facilmente, manifestando-se de maneira oculta, sendo o motivo de pouco se falar sobre o assunto dentro das famílias e mesmo na sociedade, considerado uma ato vergonhoso (SEGAL, 2009). 
Assim, o suicídio abrange diversos fatores os quais podem ser observados precocemente e consequentemente, prevenidos. Por esse assunto ser considerado um tabu, e para muitas culturas religiosas, um "pecado", o tema ainda não é conversado abertamente e visto com um certo medo dentro das famílias, assim a falta de conhecimento do assunto por parte dos profissionais de saúde surgem como uma barreira para a sua prevenção (ASSOCIAÇÃO BRASILEIRA DE PSIQUIATRIA, 2014).

\section{Suicídio do Idoso}

O idoso por sua vez também pode apresentar comportamentos e ideações suicidas, levando em consideração seu ciclo vital e os vários acontecimentos que podem levar ao desencadeamento dessas atitudes (CAVALCANTE \& MINAYO, 2015). Os episódios vivenciados por pessoas idosas visto como difíceis, podem ser analisados de diversos âmbitos. Assim, as relações familiares (falta de atenção pelos mesmos, afrouxamento de contato), a falta de participação no meio social, o impacto causado por mudanças e percas e os estigmas sociais podem levar os idosos a desenvolver comportamentos preditores do suicídio (CAVALCANTI et al. 2015).

Assim como as ideações e as tentativas, o suicídio consumado vem aumentando na população idosa, levando pesquisadores e estudiosos a investigarem esse fenômeno em indivíduos nessa fase da vida (ASSIS et al. 2012). Conhecer o assunto, entendendo seus aspectos epidemiológicos segundo Cassorla (1998, apud ASSIS et al. 2012) contribui para ações de prevenção, analisando seus complexos fatores, por meio de métodos encontrados através do conhecimento obtido em estudos.

Nesse sentido, levando em consideração a citação de Cavalcante et al. (2015) a respeito dos preditores do suicídio, Lima et al. (2013) afirma que os conflitos familiares, doenças crônicas, solidão e aspectos depressivos são os maiores responsáveis por causas de suicídio de idosos, onde os métodos utilizados variam entre países, sendo considerado as armas de fogo, o uso de substâncias e o enforcamento, como os principais meios encontrados em estudos sobre o suicídio entre idosos.

Idosos que comentem suicídio vivem, na maioria das vezes, sozinhos dificultando assim, o acesso a tempo para serem ajudados e impedidos de tentarem contra a própria vida. Por isso, 
fatores sociais fazem parte das principais causas de morte por suicídio entre idosos, destacando, por pesquisas realizadas no assunto, a invalidez, o isolamento social e o aparecimento de doenças crônicas (CAVALCANTE; MINAYO, 2012).

\section{Fatores Familiares e Sociais}

Para que a expectativa de vida da população aumente, tem-se buscado melhores condições de vida e avanços no campo da saúde (IBGE, 2009 apud GONÇALVES et al. 2013). Assim, qualidade de vida relaciona-se com o bem-estar do indivíduo, envolvendo vários aspectos na dimensão física, psicológica e social. A vida do idoso é constituída por várias experiencias, que são vividas de forma particular, envolvendo as perdas metais e cognitivas, e as mudanças sociais que afetam sua autonomia e independência. Esse processo pode ser negativo para o idoso e também para a família (GONÇALVES et al. 2013).

A dinâmica familiar em que o idoso está inserido é de suma importância para compreender os processos envolvidos nos casos de suicídio. Essa relação familiar inclui o afeto existente, os valores e também a existência de conflitos e rejeições na construção dos laços familiares. Todas a mudanças em sua estrutura psicológica e emocional são afetadas quando inexisti um suporte para completo enfrentamento das mudanças ocorridas, deixando o idoso em estado vulnerável ao suicídio (SILVA et al. 2015).

Sem um apoio familiar, os idosos são deixados de lado e em seu convívio não são percebidos de modo particular, assim seus problemas não são ouvidos, sua expectativa de vida diminui e em alguns casos seu grito de socorro é ignorado, sendo encontrado no suicídio a única forma de amenizar esse sofrimento.

Assim, Silva et al. (2015) cita a pesquisa realizada entre a associação dos conflitos familiares com o suicídio no idoso, demonstrando múltiplos fatores como perdas significativas, mudanças geográficas para longe dos familiares, abandono, perda da autonomia para cuidar dos próprios negócios, violência física ou psicológica, assim como os conflitos entre os familiares. O que os idosos esperam de seus familiares são afeto, espaço para liberdade, compreensão e acolhimento; todo esse processo permite uma melhor qualidade de vida para o idoso.

A violência familiar contra o idoso acarreta prejuízos em sua qualidade de vida, sendo um preditor para o desencadeamento de doenças físicas e psicológicas (COSTA, 2006 apud SILVA 
E DIAS 2016). O aspecto citado pelo autor demostra o fator da violência contra o idoso, assim pode ser destacado a importância do apoio da equipe de saúde, levando-os a procurarem ajuda quando forem submetidos a episódios de violência, o que pode levar a diminuição desses fatores preditores de comportamentos e atos suicida no idoso (GRILO; JÚNIOR, 2015).

Percebe-se que definir um fator, uma circunstância ou até mesmo acontecimento que possa levar ao suicídio é uma tarefa difícil, pois diversos episódios podem servir de causa para o ato. As causas possuem características distintas, sem surgir de modo isolado, nisto não se pode determinar o fator determinante do suicídio, pois tudo depende de como a situação é enfrentada pelo indivíduo (DURKHEIM, 2007).

O idoso dentro do contexto social, se depara com algumas mudanças negativas, incluindo a dependência física, o afastamento do mercado de trabalho e o surgimento de doenças crônicas. Todo esse processo se apresenta como morte subjetiva, gerando sentimentos de inutilidade e afastamento social, que pode levar a uma depressão, sendo uma das principais causas de suicídio de idosos (SOUSA et al. 2013).

Autópsias psicossociais, mostraram algumas circunstâncias associadas ao suicídio de idosos, destacado os transtornos mentais, depressão, uso abusivo de álcool e estigmas sociais relacionados a velhice (SERVIO E CAVALCANTE, 2013 apud SÉVIO, 2015). Todos os fatores citados possuem ligações com a vulnerabilidade vivenciada por a população idosa, sendo observado por a ótica do próprio idoso, que em muitas vezes não aceitam a fase vivenciada, exagerando assim em seus comportamentos sociais e individuais.

\section{A Contribuição da Psicologia no Processo de Prevenção ao Suicídio}

Falar sobre suicídio em qualquer contexto, é considerado complicado por todo processo envolvido no ato. Assim, destaca-se a importância de compreender a morte por suicídio como algo específico e determinado na sociedade atual, envolvendo os determinantes pessoais e coletivos, assim como a forma que o encaramos. Discutir sobre a morte vai de encontro com aquilo que a ciência busca: prolongar a vida, então tratar da questão do suicídio dentro de uma sociedade capitalista, tornou-se um desafio para a psicologia, pois ela deve buscar compreender o ato e as tentativas, e não esconder os determinantes, generalizando-os utilizando senso comum para explicar os motivos do ato (NETTO, 2013). 
Apenas discutir sobre suicídio, segundo Fukumitsu (2014) não dá as informações necessárias para que o profissional de psicologia contribua no processo de intervenção, assim, é de suma importância que o terapeuta ao receber um paciente com crises suicida, se interesse pelo seu sofrimento, demostrando empatia com seu sofrimento, onde a relação estabelecida não busca a cura da dor, mas facilitar no manejo do sofrimento do paciente, entendendo que pode não se suficiente o processo terapêutico.

Mas nem sempre o profissional de psicologia se atenta para o fato de que a prevenção não ocorre apenas em momentos de crise, mas como uma forma de promover entre os indivíduos, a valorização da vida (NETTO, 2013). A prevenção ocorre em conjunto com a família e com outros profissionais da saúde, podendo envolver toda comunidade nesse processo (FUKUMITSU, 2014).

Bastos (2009) discuti a importância dos vínculos familiares e sociais na compreensão do suicídio como um processo psicossocial. Desta maneira, percebe-se a relevância de entender o contexto que indivíduo está inserido para elaborar estratégias de prevenção.

Percebendo que o processo para o desencadeamento de ideações suicidas, envolve todo o âmbito que envolve o indivíduo, a prevenção também começa no âmbito coletivo (BOTEGA, et al. 2006). Conhecer os familiares do paciente em crise suicida, ajudará no processo de prevenção, sendo um trabalho desenvolvido para identificar os riscos não apenas no paciente, mas nos familiares que podem possuir demanda envolvida, mas que está depositada apenas no indivíduo, destacando que após o suicídio, as pessoas ao redor são afetadas (WERLANG, 2013).

O trabalho do psicólogo frente a pacientes em crises suicidas ou com ideações, enfrenta a questão do sigilo, podendo ser feito com o paciente um contrato de quebra, onde se escolhe duas pessoas para deixar como contato se algo acontecer, sendo um apoio para o trabalho desenvolvido pelo psicólogo. Essa ferramenta de trabalho envolve a disponibilidade do psicólogo em compreender o sofrimento do paciente, respeito por sua escolha naquele momento e também tolerância ao pensar na possibilidade de fracassar na sua intervenção, sem tomar para si a responsabilidade de salvar vidas (FUKUMITSU, 2014).

Diante da crise suicida, o psicólogo aparece como figura de grande importância no processo de intervenção e de manejo com os familiares envolvidos no processo, destacando que seu trabalho não ocorre apenas em situações emergentes, mas no processo de promover a qualidade de vida dos indivíduos em geral, percebendo que o apoio psicológico de paciente em 
sofrimento, contribui para que as ideações que podem ser ocultas para os que cercam, possam ser entendidas e muitas vezes deixadas de lado pelo paciente que pensa em tirar sua própria vida.

\section{Metodologia}

Este estudo constitui numa pesquisa bibliográfica, que segundo Marconi e Lakatos (2003), pode abarcar todos estudos já publicados sobre o tema em questão, com o propósito de levar o pesquisador a ter contato com o que já foi estudado sobre o assunto pesquisado, permitindo que o conhecimento seja ampliado a partir de um novo olhar sobre o assunto, gerando novas conclusões.

Utilizando a abordagem qualitativa que busca, segundo Yin (2016) explicar acontecimentos da vida cotidiana, através de concepção existentes sobre o assunto, podendo assim, ampliar conceitos. Nisto a pesquisa coleta dados de várias fontes, para obtenção dos dados do estudo, é trazer a reflexão do pesquisador sobre o que encontrou em sua pesquisa, assim como a confiabilidade sem utilizar-se de métodos estatísticos.

Assim, a pesquisa iniciou com uma busca de estudos sobre o assunto a ser estudado, utilizando-se de bases de dados como Scientific Eletronic Library On Line - Scielo, PePsic Periódicos Eletrônicos em Psicologia, BVS - Biblioteca Virtual em Saúde, Google Acadêmico, Index Digital, sites do Ministério da Saúde (cartilhas e manuais), Conselho Federal de Psiquiatria, assim como em livros, no período de julho a agosto de 2017. As palavras chaves utilizadas na pesquisa foram: idosos, suicídio, ideação suicida, cuidador, idoso e família, as quais serviram de base para a busca dos materiais aplicados no estudo.

\section{Considerações Finais}

A partir do estudo, que teve como objetivo identificar o papel do cuidador na identificação dos fatores relacionados ao suicídio de idosos, foi contemplado as condições que levam os familiares a buscarem um cuidador para ajudarem o idoso em suas atividades diárias e promoverem bem-estar. Assim, foi demostrado os processos envolvidos que podem anteceder o suicídio do idoso e a contribuição da psicologia no processo de prevenção. 
Através do estudo observou-se que aos cuidadores possuem papel importante no desenvolvimento do bem-estar do idoso lhe, proporcionando qualidade de vida, e autonomia. Desse modo, ao se dedicarem nesse cuidado podem perceber seus comportamentos suicidas e informar aos familiares. Nisto, atender as necessidades básicas do idoso, inseri-lo em um ambiente familiar agradável, sem conflitos, permitindo que ele perceba que é amado e acolhido por a família dentro de suas limitações e dependência, também contribui para a prevenção do suicídio.

O objetivo geral da pesquisa é exposto no estudo, destacando o papel de um cuidador, familiar ou formal, na vida do idoso, apontando que a falta de afeto, cuidado dos familiares e a presença de conflitos, são fatores enfatizados na predisposição das ideações e comportamentos levando ao suicídio. Verificando desta forma, a importância do acolhimento familiar, e também social, no processo de enfrentamento das mudanças ocorridas nessa fase da vida, que pode ser percebida pelos cuidadores, através da convivência.

Por fim, o trabalho desenvolvido apresentou-se como contribuição para o entendimento acerca dos processos ocorridos no suicídio, o papel dos cuidadores na vida do idoso e de seus familiares, percebendo a falta de conhecimento da população e no meio acadêmico sobre o tema proposto. Assim, pesquisar sobre o assunto proposto, trouxe a reflexão da falta de estudos sobre o público específico, a falta de conhecimento da população sobre a complexidade do tema estudado e de como o profissional de psicologia pode atuar nesse processo de intervenção, não apenas com o indivíduo em contextos de crise, mas junto a família na compreensão dos fatores que levam o idoso a desenvolver as ideações e comportamentos suicidas.

Sem esgotar o tema, o estudo contribui para o desenvolvimento de novas pesquisas, abordando as informações encontradas, sem limitar-se as dificuldades encontradas, mas contribuindo para a reflexão, dos familiares e da sociedade, levando-os a desenvolverem uma melhor convivência e uma qualidade de vida para o idoso, buscando caminhos para minimizar os impactos sociais nessa fase da vida. 


\section{Referências}

ARAÚJO, L. C; VIEIRA, K. L. F; COUTINHO, M. P. L. Ideação suicida na adolescência: um enfoque psicossociológico no contexto do ensino médio. Psico-USF, v. 15, n. 1, p. 47-57, jan./abr. 2010. Disponível em: <http://www.scielo.br/pdf/pusf/v15n1/06.pdf > Acesso em 12 agos. 2017

ASSOCIAÇÃO BRASILEIRA DE PSIQUIATRIA. Suicídio: informando para prevenir / Comissão de Estudos e Prevenção de Suicídio. - Brasília: CFM/ABP, 2014. Disponível em: $<$ https://www.cvv.org.br/wpcontent/uploads/2017/05/suicidio_informado_para_prevenir_abp _2014.pdf> Acesso em 16 set. 2017

BARBOSA, A. K. L; PARENTE, T. D. L; BEZERRA, M. M. M; MARANHÃO, T. L. G. Bullying e sua relação com o suicídio na adolescência. Id on Line Rev. Psic. V.10, N.31, 2016. Disponível em: <http://idonline.emnuvens.com.br/id> Acesso em: 23 set. 2017

BASTOS, R. L. Suicídios, psicologia e vínculos: uma leitura psicossocial. Psicologia USP, São Paulo, janeiro/março, 2009. Disponível em: <http://www.scielo.br/pdf/pusp/v20n1/v20n1a05.pdf> Acesso em 11 nov. 2017

BATISTA, M. P. P; BARROS, J. O; ALMEIDA, M. H. M; MÂNGIA, E. F; LANCMAN, S. Acompanhantes de idosos: reflexão sobre sua prática. Rev Saúde Pública, 2014. Disponível em: <http://www.scielosp.org/pdf/rsp/v48n5/pt_0034-8910-rsp-48-5-0732.pdf> Acesso em: 11 set. 2017

BELlASAlMA, A. C. M; SELEGHIM, M. R; MATIAS, T. A. F; OLIVEIRA, M. L. F. Caracterização das tentativas de suicídio entre idosos. Cogitare Enferm, 2012. Disponível em: <http://revistas.ufpr.br/cogitare/article/view/25815> Acesso em 22 set. 2017

BOTEGA, N. J; LEÓN, L, M; OLIVEIRA, H. B; BARROS, M. B. A; SILVA, V. F; DALGALARRONDO, P. Prevalências de ideação, plano e tentativa de suicídio: um inquérito de base populacional em Campinas, São Paulo, Brasil. Cad. Saúde Pública, Rio de Janeiro, dez, 2009. Disponível em: <http://www.scielo.br/scielo.php?script=sci_arttext\&pid=S0102311X2009001200010> Acesso em 21 set. 2017

WERLANG, B. S. G; CAIS, C. F. S; MACEDO, M. M. K. Prevenção do comportamento suicida. PSICO, Porto Alegre, v. 37, n. 3, pp. 213-220, set./dez. 2006. Disponível em: <http://revistaseletronicas.pucrs.br/revistapsico/ojs/index.php/revistapsico/article/view/1442> Acesso em: 11 nov. 2017

BRASIL. Ministério da Saúde. Prevenção do suicídio: manual dirigido a profissionais das equipes de saúde mental. Brasília, 2006. Disponível em: <https://www.cvv.org.br/wpcontent/uploads/2017/05/manual_prevencao_suicidio_profissionais_saude.pdf > Acesso em 15 set. 2017 
BRASIL. Ministério da Saúde. Secretaria de Atenção à Saúde. Secretaria de Gestão do Trabalho e da Educação na Saúde. Guia prático do cuidador / - Brasília: Ministério da Saúde, 2008.2 Disponível em: <http://bvsms.saude.gov.br/bvs/publicacoes/guia_pratico_cuidador.pdf> Acesso em 15 set. 2017

BRASIL. LEI N 7332 DE 14 DE JULHO 2016. Estabelece normas para o exercício da atividade profissional de cuidador de pessoa idosa, no âmbito do estado do rio de janeiro e dá outras providências. Disponível em <http://alerjln1.alerj.rj.gov.br/CONTLEI.NSF/e9589b9aabd9cac8032564fe0065abb4/a488aec 8a6aa75a883257ff1005af5e8?OpenDocument> Acesso em: 07 de set. 2017

CAVALCANTE, F. G; MINAYO, M. C. S. Estudo qualitativo sobre tentativas e ideações suicidas com 60 pessoas idosas brasileiras. Ciência e Saúde coletiva, 2015. Disponível em: $<$ http://www.scielo.br/scielo.php?pid=S1413-

$81232015000601655 \&$ script=sci_abstract\&tlng=pt $>$ Acesso em 20 set. 2017

Autópsias psicológicas e psicossociais de idosos que morreram por suicídio no Brasil. Revista Ciência e Saúde Coletiva, 2012. Disponível em: <http://www.scielo.br/scielo.php?script=sci_arttext\&pid=S1413-81232012000800015> Acesso em 18 agos. 2017

Suicídio entre pessoas idosas: revisão da literatura. Rev Saúde Pública 2010. Disponível em: <http://www.scielo.br/pdf/rsp/v44n4/20.pdf > Acesso em: 08 set. 2017

CARVALHO, A. A. Reflexões acerca das representações sociais em Durkheim e o estudo sobre a AIDS. Caos - Revista Eletrônica de Ciências Sociais N. 18 2011. Disponível em <https://www.google.com.br/search?q=Reflexoes> Acesso em: 01 set. 2017

COLOMÉ, I. C. S. MARQUI, A. B. T. JAHN, A. C. RESTA, D. G. CARLI, R. WINCK, M. T. Cuidar de idosos institucionalizados: características e dificuldades dos cuidadores. Rev. Eletr. Enf. [Internet] 2011. Disponível em: <https://www.fen.ufg.br/fen_revista/v13/n2/v13n2a17.htm> acesso em 13 set. 2017.

COMBINATO, C. S; QUEIROZ, M. S. Morte: uma visão psicossocial. Estudos de Psicologia, 2006. Disponível em: <http://www.scielo.br/scielo.php?pid=S1413294X2006000200010\&script=sci_abstract\&tlng=pt> Acesso em 20 se. 2017

CONCEIÇÃO, L. F. S. Saúde do idoso: orientações ao cuidador do idoso acamado. Rev Med Minas Gerais, 2010. Disponível em: <http://dietpharma.com.br/blog/wpcontent/uploads/2015/04/Sa\%C3\%BAde-do-idoso-orienta\%C3\%A7\%C3\%B5es-ao-cuidadordo-idoso-acamado.pdf> Acesso em 27 out. 2017

COSTA, L. D. Concepção de representação na sociologia clássica. Re. Esp. Academ. n. 172, 2015. Disponível em: <http://www.periodicos.uem.br/ojs/index.php/EspacoAcademico/article/view/27294> Acesso em 22 agosto. 2017 
COUTO, A. M; CASTRO, E. A. B; CALDAS, C. P. Vivências de ser cuidador familiar de idosos dependentes no ambiente domiciliar. Rev Rene. 2016. Disponível em: <http://www.periodicos.ufc.br/rene/article/view/2624> Acesso em 17 out. 2017

DURKHEIM, E. (1858-1917). As regras do método sociológico. Trad. Paulo Neves. Rev. Eduardo Brandão. $3^{\circ}$ ed - São Paulo: Martins Fontes, 2007. (coleção tópicos).

FIGUEIREDO, A. E B; SILVA, R. M; VIEIRA, L. J. E. S; MANGAS, R. M. N; SOUSA, G. S; FREITAS, J. S; CONTE, M; SOUGEY, E. B. É possível superar ideações e tentativas de suicídio? Um estudo sobre idosos. Ciência e Saúde coletiva, 2015. Disponível em: <https://www.researchgate.net/publication/279160646_E_possivel_superar_ideacoes_e_tentat ivas_de_suicidio_Um_estudo_sobre_idosos> Acesso em 23 agos. 2017

FREITAS, I. C. C; PAULA, K. C. C; SOARES, J. L; PARENTE, A. C. M. Convivendo com o portador de Alzheimer: perspectiva do familiar cuidador. Rev. Bras Enferm, Brasília, 2008. Disponível em: <http://www.scielo.br/pdf/reben/v61n4/18.pdf> Aceeso em 14 out. 2017

FUKUMITSU, K. O. O psicoterapeuta diante do comportamento suicida. Psicologia USP, v. 25, n. 3, 270-275, 2014. Disponível em: <http://www.scielo.br/pdf/pusp/v25n3/0103-6564pusp-25-03-0270.pdf> Acesso em 11 nov. 2017

GONÇALVES, L. T. H; LEITE, M. T; HILDEBRAND, L. M; BISOGNO, S. C; BIASUZ, S; FALCADE, B. L. Convívio e cuidado familiar na quarta idade: qualidade de vida de idosos e seus cuidadores. Rev. Bras. Geriatr. Gerontol, Rio de Janeiro, 2013; 16(2):315-325 Disponível em: <http://www.scielo.br/scielo.php?script=sci_arttext\&pid=S180998232013000200011> Acesso em 10 out. 2017

GOMEZ. G; LOPEZ, L. R. Propuesta de preparación para cuidadores asistenciales como promotores de salud. Medisur [revista en Internet]. 2015]. Disponível em <http://www.medisur.sld.cu/index.php/medisur/article/view/3064> acesso em: 10 set. 2017

GRILO, P. M. S; JÚNIOR, I. L. Maus-tratos a idosos: perfil das vítimas, vínculo com o agressor e atuação dos profissionais. Estud. interdiscipl. Envelhec. Porto Alegre, v. 20, n. 2, p. 611-624, 2015. Disponível em: <http://www.seer.ufrgs.br/RevEnvelhecer/article/view/50955> Acesso em 18 out. 2017

KARSCH, U. M. Idosos dependentes: famílias e cuidadores. Cad. Saúde Pública, Rio de Janeiro, 2003. Disponível em: <http://www.scielo.br/scielo.php?pid=S0102311X2003000300019\&script=sci_abstract\&tlng=pt> Acesso em 01 out. 2017

KOVÁCS, M. J; FUKUMITSU, K. O. O luto por suicídios: uma tarefa da posvenção. Revista Brasileira de Psicologia, Salvador, Bahia, 2015. Disponível em: <http://revpsi.org/wpcontent/uploads/2015/12/Fukumitsu-Kov\%C3\%A1cs-2015-O-luto-por-suic\%C3\%ADdiosuma-tarefa-da-posven\%C3\%A7\%C3\%A3o.pdf> Acesso em 19 set. 2017 
LAKATOS, E. M; MARINA, A. M. Fundamentos de metodologia científica. - 5. ed. - São Paulo: Atlas 2003.

LEME, J. B; OLIVEIRA, D. C; CRUZ, K. C. T; HIGA, C. M. H; D’ELBOUX, M. J. Grupo de apoio a cuidadores familiares de idosos: uma experiência bem sucedida. Cienc Cuid Saude 2011. Disponível em: <eduem.uem.br/ojs/index.php/CiencCuidSaude/article/download/18318/pdf> Acesso em 10 set. 2017

LIMA, F. M; NETO, F. A. M; MELO, A. A. G; QUEIROZ, A. F. B; PAIVA, S. O. C. Suicídio em idosos no Recife (PE): Um estudo sobre mortalidade por causas externa. Revista Kairós Gerontologia,16(5), pp. 255-267, 2013. Disponível em: $<$ https://revistas.pucsp.br/index.php/kairos/article/viewFile/18647/13835> Acesso em 25 set. 2017

MELEIRO, A; SANTOS, C. M; SOUSA, K. A. Como prevenir o rico e a tentativa de suicídio. 2009 Disponível em: <http://www.medicinanet.com.br/conteudos/revisoes/2398/como_prevenir_o_risco_e_a_tenta tiva_de_suicidio>htm Acesso em: 30 de set. 2017

MINAYO, M. C. S; TEIXEIRA, S. M. O; MARTINS, J. C. O. Tédio enquanto circunstância potencializadora de tentativas de suicídio na velhice. Estudos de Psicologia, 2016. Disponível em: <http://www.scielo.br/scielo.php?pid=S1413294X2016000100036\&script=sci_abstract\&tlng=pt> Acesso em 18 set. 2017

MINAYO, M. C. S; PINTO, L. W; ASSIS, S. G; CAVALCANTE, F. G; MANGAS, R. M. N. Tendência da mortalidade por suicídio na população brasileira e idosa, 1980-2006. Rev Saúde Pública, 2012. Disponível em: <http://www.scielo.br/scielo.php?script=sci_arttext\&pid=S0034-89102012000200012> Acesso em 12 out. 2017

MINAYO, M. C. S; CAVALCANTE, F. G; MANGAS, R. M. N; SOUZA, J. R. A. Autópsias psicológicas sobre suicídio de idosos no Rio de Janeiro. Ciência e Saúde coletiva, $2012 . \quad$ Disponível em: <https://pdfs.semanticscholar.org/a4e0/0ce7f96117e71024a8a4f5d20e4ea7757f66.pdf> Acesso em 23 set. 2017

MIRANDA, G. M. D; MENDES, A. C. G; SIVAL, A. L. A. O envelhecimento populacional brasileiro: desafios e consequências sociais atuais e futuras. Rev. Bras. Geriatr. Gerontol, Rio de Janeiro, 2016. Disponível em:

MOOZ, E. D; VIEIRA, F. M. C. Suicídio: uma pandemia silenciosa. V Congresso nacional de pesquisa em ciências sociais aplicadas. 2016 Disponível em: <http://www.unioeste.br/eventos/conape/> Acesso em 22 out. 2017

NETTO, N. B; WERLANG, B; RIGO, S. C. O suicídio e os desafios para a psicologia. Conselho Federal de Psicologia. - Brasília: CFP, 2013 
NOGUEIRA, P. C; RABEH S. A. N; CALIRI, M. H. L; DANTAS, R. A. S; HAAS, V. J. Sobrecarga do cuidado e impacto na qualidade de vida relacionada à saúde de cuidadores de indivíduos com lesão medular. Rev. Latino-Am. Enfermagem, 2012. Disponível em: <http://www.scielo.br/pdf/rlae/v20n6/pt_06.pdf> Acesso em 11 set. 2017

NETO, F. A. M; MELO, A. A. G; QUEIROZ, A F. B; PAIVA, S. O. C; LIMA, F. M. Suicídio em idosos no Recife (PE): Um estudo sobre mortalidade por causas externa. Revista Kairós Gerontologia, São Paulo, 2013. Disponível em: <https://revistas.pucsp.br/index.php/kairos/article/view/18647> Acesso em 24 set. 2017

NEN, J. D. C; ARAÚJO, L. L; LOPES, A. O. S; CÂNDIDO, A. S. C. Qualidade de vida de cuidadoras formais de idosos. Revista Baiana de Enfermagem, Salvador, v. 29, n. 2, p. 156-163, 2015. Disponível em: <https://www.cadernocrh.ufba.br/index.php/enfermagem/article/download/12548/pdf_123> Acesso em 9 out. 2017

SCALCO, J. C.; TAVARES, K. O; VIEIRA, L; SILVA, J. R; BASTOS, C. C. C. B. O dia a dia de cuidadores familiares de idosos dependente. Revista Kairós Gerontologia. Online, 2013. <https://revistas.pucsp.br/index.php/kairos/article/viewFile/19072/14233> Acesso 3 out. 2017

SEGAL, J. Aspectos genéticos do comportamento suicida. Tese [doutorado] Universidade Federal do Rio Grande do Sul. Porto Alegre, 2009. Disponível em: <https://www.lume.ufrgs.br/bitstream/handle/10183/17380/000716287.pdf?sequence=1> Acesso em 3 agos. 2017

SÉRVIO, S. M. T. Velhices Fragilizadas na Contemporaneidade: Uma Investigação sobre as Circunstâncias Potencializadoras de Tentativas de Suicídio em Idosos de Teresina. Dissertação (mestrado) - Universidade de Fortaleza, 2015. Disponível em: <http://pepsic.bvsalud.org/scielo.php?script=sci_arttext\&pid=S2176-48912015000100008> Acesso em 27 agos. 2017

CAVAlCANTE, A. C. S. Retratos de Autópsias Psicossociais Sobre Suicídio de Idosos em Teresina. Psicologia: ciência e profissão, 2013. Disponível em: $<$ http://introducaoapsicologiaunb.blogspot.com.br/2014/10/retratos-de-autopsiaspsicossociais.html> Acesso em 28 agos. 2017

SILVA, R. M; MANGAS, R. M. N; FIGUEIREDO, A. E. B; VIEIRA, L. J. E. S; SOUSA, G. S; CAVALCANTI, A. M. T. S; APOLINÁRIO, A. V. S. Influências dos problemas e conflitos familiares nas ideações e tentativas de suicídio de pessoas idosas. Ciência e Saúde coletiva, 2015. Disponível em: <http://www.scielo.br/pdf/csc/v20n6/1413-8123-csc-20-061703.pdf> Acesso em 19 set. 2017

SILVA, C. F. S; DIAS, C. M. S. C. Violência Contra Idosos na Família: Motivações, Sentimentos e Necessidades do Agressor. Psicologia: Ciência e Profissão, Jul/set. 2016. Disponível em: <http://www.scielo.br/pdf/pcp/v36n3/1982-3703-pcp-36-3-0637.pdf> Acesso em 3 out. 2017 
SOUSA, G. S; SILVA, R. M; FIGUEIREDO, A. E. B; MINAYO, M. C. S; VIEIRA, L. J. E. S. Circunstâncias que envolvem o suicídio de pessoas idosa. Interface comunicação saúde educação, 2013. Disponível em: <http://www.scielo.br/scielo.php?pid=S141432832014000200389\&script=sci_abstract\&tlng=pt $>$ Acesso em 4 set. 2017

SOUZA, L. D. M; ORES, L; OLIVEIRA, G. T; CRUZEIRO, A. L. S; SILVA, R. A; PINHEIRO, R. T; HORTA, B. L. Ideação suicida na adolescência: prevalência e fatores associados. J Bras Psiquiatr. 2010. Disponível em: <http://www.scielo.br/scielo.php?script=sci_arttext\&pid=S0047-20852010000400004> Acesso em 18 set. 2017

TURECKI, G. comportamento impulsivo-agressivo. Rev Bras Psiquiatr - Genética - vol. 21 outubro $1999 . \quad$ Disponível em:

<http://www.scielo.br/scielo.php?script=sci_arttext\&pid=S1516-44461999000600006>

Acesso em 19 agos. 2017

YIN, R. K. Pesquisa qualitativa do início ao fim. [Recurso eletrônico]. Trad. Daniel Bueno; Rev. Sist. Dirceu da Silva - Porto Alegre: Penso, 2016.

\section{Como citar este artigo (Formato ABNT):}

ALCÂNTARA, Maria R. de Oliveira; MARANHÃO, Thércia L. G.; MARINHO, Ana Olívia de O.; MACEDO, Leonarda C. de. O Papel do Cuidador na Identificação dos Fatores Relacionados ao Suicídio de Idosos. Id on Line Revista Multidisciplinar e de Psicologia, 2018, vol.12, n.39, p. 674694. ISSN: 1981-1179.

Recebido: 19.01 .2018

Aceito: 246.01.2018 